\title{
A MODEL FOR HIGHER EDUCATION CAMPUS HEALTH SERVICES
}

\section{Authors:}

Esmeralda J. Ricks ${ }^{1}$ Johanita Strümpher ${ }^{1}$ Dalena van Rooyen ${ }^{1}$

\section{Affiliations: \\ ${ }^{1}$ Department of Nursing Science, Nelson Mandela Metropolitan University, North campus, South Africa.}

\section{Correspondence to:} Esmeralda Ricks

email:

esmeralda.ricks@nmmu.

ac za

\section{Postal address:}

c/o The Nursing Science

Department, Building

Nelson Mandela 206,

Metropolitan University, North campus, Private Bag X77000, Port Elizabeth 6013 , South Africa

\section{Keywords:}

healthcare consumer; healthcare needs; holistic healthcare; primary health care; theory-generation

\section{Dates:}

Received: 14 Oct. 2009

Accepted: 17 Mar. 2010

Published: 03 Nov. 2010

How to cite this article:

Ricks, E.J., Strümpher J. \&

Van Rooyen, D., 2010, 'A model for higher education campus health services' Health SA Gesondheid 15(1), Art. \#508, 7 pages. DOI: 10.4102/hsag.v15i1.508

\section{This article is available}

http:/ / www.hsag.co.za
(C) 2010. The Authors. Licensee: OpenJournals Publishing. This work is licensed under the Creative Commons Attribution License.

\section{ABSTRACT}

This study was undertaken in order to develop a holistic healthcare model that would assist registered nurses who are employed at a higher education campus' health service to render a healthcare service relevant to the healthcare needs of the campus healthcare consumers.

A theory-generative, qualitative, explorative, descriptive and contextual research design for theory generation was used to develop a holistic healthcare model for a higher education campus' health service. It became evident throughout the study that the participants experienced a need for a more comprehensive healthcare service on campus. The main concepts of holistic healthcare were identified from the information obtained from the in-depth, focus group interviews that were conducted with the participants. The process of theoretical model generation was conducted according to the steps of theory generation as proposed by Walker and Avant (1995:39), namely that of concept analysis, the placing of concepts in relationships, a description of the model and guidelines to operationalise the model.

This model provides a structured holistic healthcare frame of reference for registered nurses employed in a campus health service at a Higher Education Institution (HEI) and could be used to assist all campus healthcare consumers to become balanced whole persons who are able to realise their dreams and maintain consistency with regard to optimal health and capacity.

\section{OPSOMMING}

Hierdie studie is onderneem om teneinde ' $n$ holistiese gesondheidsorgmodel te ontwikkel wat geregistreerde verpleegkundiges, werksaam by 'n hoër onderwys kampusgesondheidsorgdiens, kan help om 'n gesondheidsorgdiens te kan lewer wat relevant is tot die gesondheidsbehoeftes van die kampusgesondheidsorg verbruikers.

'n Teorie-generende, kwalitatiewe, eksplorerende, beskrywende en kontekstuele navorsingsontwerp vir teorie genering is gebruik om 'n holistiese gesondheidsorgmodel vir hoër onderwys kampusgesondheidsorgdienste te ontwikkel. Tydens die studie het dit duidelik geword dat die deelnemers ' $n$ behoefte het daaraan om 'n meer omvattende gesondheidsorgdiens op kampus te ervaar. Die hoof konsepte van holistiese gesondheidsorg was geïdentifiseer vanuit die data wat verkry was deur die in-diepte fokusgroep onderhoude wat met die deelnemers gevoer is. Die proses van model-generering is uitgevoer volgens die stappe soos voorgestel deur Walker en Avant (1995:30) naamlik dit van konsep-analise, die plasing van konsepte in verhoudings, die beskrywing van die model en die riglyne om die model operatief te maak.

Die model maak voorsiening vir 'n gestruktureerde holistiese gesondheidsorgraamwerk wat as verwysing kan dien vir geregistreerde verpleegkundiges werksaam by ' $\mathrm{n}$ kampus gesondheidsorgdiens by 'n Hoër Onderwys Instansie (HOI) en kan gebruik word om alle kampus gesondheidsorgverbruikers te help om gebalanseerde, heel persone te word wat in staat is om hul drome te vervul en konsekwentheid met betrekking tot optimale gesondheid en kapasiteit te handhaaf.

\section{INTRODUCTION}

Campus health services have evolved since 1859 as a result of a sentiment expressed by President Stearns, the head of Amherst College in the United States of America, who noted that many students abandoned their studies at Higher Education Institutions (HEIs) because of poor health. He felt the latter situation was unnecessary if proper measures were taken to prevent this situation (Patrick, Grace \& Lovato 1992:256). The first campus health service in South Africa (SA) was established almost a century later in the 1940s. A steady growth of campus health services ensued in SA and currently almost every HEI now has a campus health service (Holtzhausen 1996:26).

In South Africa, campus health services were established through trial and error and with no set guidelines, thus resulting in diverse standards being implemented on different campuses. Campus health services range in size and scope of activity, from small nurse-directed facilities to comprehensive health facilities that resemble multi-speciality group practices (Patrick et al. 1992:257). The provision of equitable, appropriate and cost-efficient healthcare services relies on healthcare data, the lack of which undoubtedly contributes to poor healthcare service planning and delivery (Patrick et al. 1992:258). Very little formal research has been conducted at HEIs in SA to establish what the healthcare needs of students and staff are and how they experience these services. The lack of such empirical data can therefore fuel the public health problems experienced; for example, sexually transmitted infections and the transmission of HIV.

The SA economy depends largely on healthy graduates entering the arena of the professional world. Equally important is the high calibre of intellectual capital within HEIs, which must be nurtured and 
protected in order for these people to remain productive and innovative. Health plays a pivotal and critical role because without health and wellness this human capital will undoubtedly suffer. Information was therefore required to establish what the actual needs of both students and staff were and also to determine what was needed at the campus health service in order to ensure optimal service delivery to the healthcare consumers. Thus a study was undertaken to develop a model that would assist registered nurses employed at a higher education campus health service to render a healthcare service relevant to the healthcare needs of the campus healthcare consumers.

Therefore the purpose of the study on which this article is based was to develop and describe a holistic healthcare model for a higher education campus health service. The model was developed utilising the steps of theory generation as proposed by Walker and Avant (1995:39), Dickoff, James and Wiedenbach (1968:423), and Chinn and Kramer (1995:108). The aforementioned steps include concept analysis, the placing of the concepts in relationships, a description of the model and guidelines to operationalise the model.

\section{THE PROCESS OF THEORY DEVELOPMENT}

The process of theory development comprises four steps, namely, concept analysis, the construction of relationship statements, a description of the model and guidelines to operationalise the model.

\section{Concept analysis}

Concept analysis was accomplished by conducting a qualitative, explorative, descriptive and contextual study to establish the experiences of campus healthcare consumers with regard to the campus health service provided on campus and also to establish how the campus healthcare providers experienced rendering the service. The perceived healthcare needs of the campus healthcare consumers were also explored and described. Data collection involved recording the in-depth interviews that were conducted with nine staff campus healthcare consumers, eleven providers and six focus group interviews with the student campus healthcare consumers.

Data were then transcribed by an independent transcriber and coded by the researcher and an independent coder. The data were analysed according to the steps suggested by Tesch (cited in Cresswell 2004:192). Measures to ensure trustworthiness and the ethical principles of beneficence, respect for human dignity and justice were adhered to throughout the study. The main concept 'holistic healthcare' was identified from the qualitative data and classified relative to the higher education context using the survey list of Dickoff et al. (1968:415-435). The list included the agent, recipient, procedure, dynamics, context and terminus, as expressed below:

- The agent is the person who performs the activity. The registered nurse, medical doctor, intern psychologist, students and staff are the agents.

- The recipient is the person(s) receiving the activity. The students and staff (including the clinic staff) are the recipients.

- The procedure refers to how the activity takes place. The procedure in this study comprised of the steps for holistic health care whereby an individual seeks help from the registered nurse to correct a health related imbalance.

- The dynamics occurring for the activity to materialise refers to the agents, recipients, resources and management.

- The context within which the activity is performed is the campus health service at an HEI.

- The terminus is the end result of the process and this terminus is a balanced whole person who is able to realise his or her aspirations and healthcare needs and maintain consistency with regard to optimum health and capacity.
Classification of the main concept created conceptual meaning that provided a foundation for developing a holistic healthcare model for a campus health service at an HEI. Walker and Avant (1995:37) state that concepts are mental constructions and are our attempts to order our environmental stimuli. Thus concepts represent categories of information that contain defining attributes. Concept analysis is a strategy that allows us to examine the attributes or characteristics of a concept. Concept analysis is therefore a formal, linguistic exercise to determine the defining attributes.

Therefore the concept 'holistic healthcare' was defined and described by firstly the individual concepts, namely 'holistic', 'health', 'care' and 'healthcare'. Both dictionary and subject definitions were used to give conceptual meaning to the main concepts identified in this study. Various dictionaries, subject textbooks, internet sites (Medline, EBSCOhost, Emerald, PubMed, Sabinet on line and Google Scholar), journals and peer-reviewed journals were explored and extensive reading was carried out to describe and understand the main concept identified. Nineteen dictionaries and sixty references were used to define the identified concepts. Chinn and Kramer (1995:40) state that this part of defining concepts and reading as much as possible is invaluable.

Once all the different instances of the concepts had been examined, a list of essential and related attributes for the concepts 'holistic', 'health', 'care' and 'healthcare' were identified. The aforementioned was necessary to identify, analyse and synthesise the attributes for the definition of the main concept 'holistic healthcare'. Chinn and Kramer (1995:94) state that the purpose of listing defining attributes is to assist one in naming the occurrence of a specific phenomenon as differentiated from another similar or related one. A model case was then constructed because it is an example of the use of the concepts that demonstrate all the defining attributes of the main concept. Basically, a model case is one that we are absolutely sure is an instance of the concept (Walker \& Avant 2005:69). After the description of the model case and its construction had been finalised, a list of essential and related attributes of 'holistic healthcare' was developed so that the concept 'holistic healthcare' could be defined within the context of the study.

Holistic healthcare is an interactive process whereby an individual seeks attention from the registered nurse to promote or restore health. The registered nurse pays serious attention to the healthcare needs of the individual by giving of herself or himself. A real concern for the quality of life of the individual is illustrated by the nurse through the rendering of an all-encompassing integrated health service that comprises promotive, preventive, curative and rehabilitative services, to provide for the healthcare needs of the individual, thus ensuring total patient care. This is achieved through assistance with disease or symptom management and equipping individuals with knowledge and skills to realise their needs. This process thus assists individuals in becoming balanced, whole persons who are harmoniously integrated (i.e. biologically, physiologically, socially, psychologically and spiritually) and who are able to adjust to various internal and external tensions in the environment. Individuals will therefore be able to realise their aspirations and maintain consistency with regard to optimum health and capacity.

The paragraph above reflect the identified essential and related attributes of the concept 'holistic healthcare' which was used to construct the relationship statements described below.

\section{The construction of relationship statements}

Concepts are the building blocks of theory and relationship statements are the mortar that glues each block to its neighbour (Walker \& Avant 2005:87). The concepts that have been identified, defined and classified will now be placed in relation 
to each other through the utilisation of relationship statements. The following relationship statements have been identified as emerging from the concepts in this model:

The campus healthcare consumer initiates consultation with the registered nurse by seeking attention either to promote or restore health. The manner in which this initial consultation is conducted will set the tone for the interactive process of holistic healthcare.

The registered nurse pays serious attention to the healthcare needs of the campus healthcare consumer and illustrates real concern for her or his quality of life. The registered nurse therefore takes a comprehensive health history and conducts a physical examination in order to make a nursing diagnosis. If the campus healthcare consumer presents a health problem that is not within the scope of practice of the registered nurse, then they will refer the individual to the relevant member of the multidisciplinary healthcare team.

Once the registered nurse has made a nursing diagnosis, she or he plans for the management of the individual, rendering an allencompassing healthcare service to ensure that all the healthcare needs of the campus healthcare consumers are provided for, thus resulting in total patient care which is culturally congruent. If the campus healthcare consumer does not respond to the treatment received from the registered nurse he or she can return to the campus health clinic for further management or referral.

The consequent resolution is the gradual disappearance of the signs and symptoms of disease or the empowerment of the individual with knowledge and skills for self-care resulting in harmonious integration of the body, mind and spirit. A balanced, whole person emerges who is able to realise her or his aspirations and to maintain consistency with regard to optimum health and capacity.

The development of relationship statements between concepts gave clarity and direction to the understanding of the phenomenon of interest.

\section{A description of the model}

An overview of the model is provided below followed by, (1) a description of the structure, (2) structural description and (3) the process of the model.

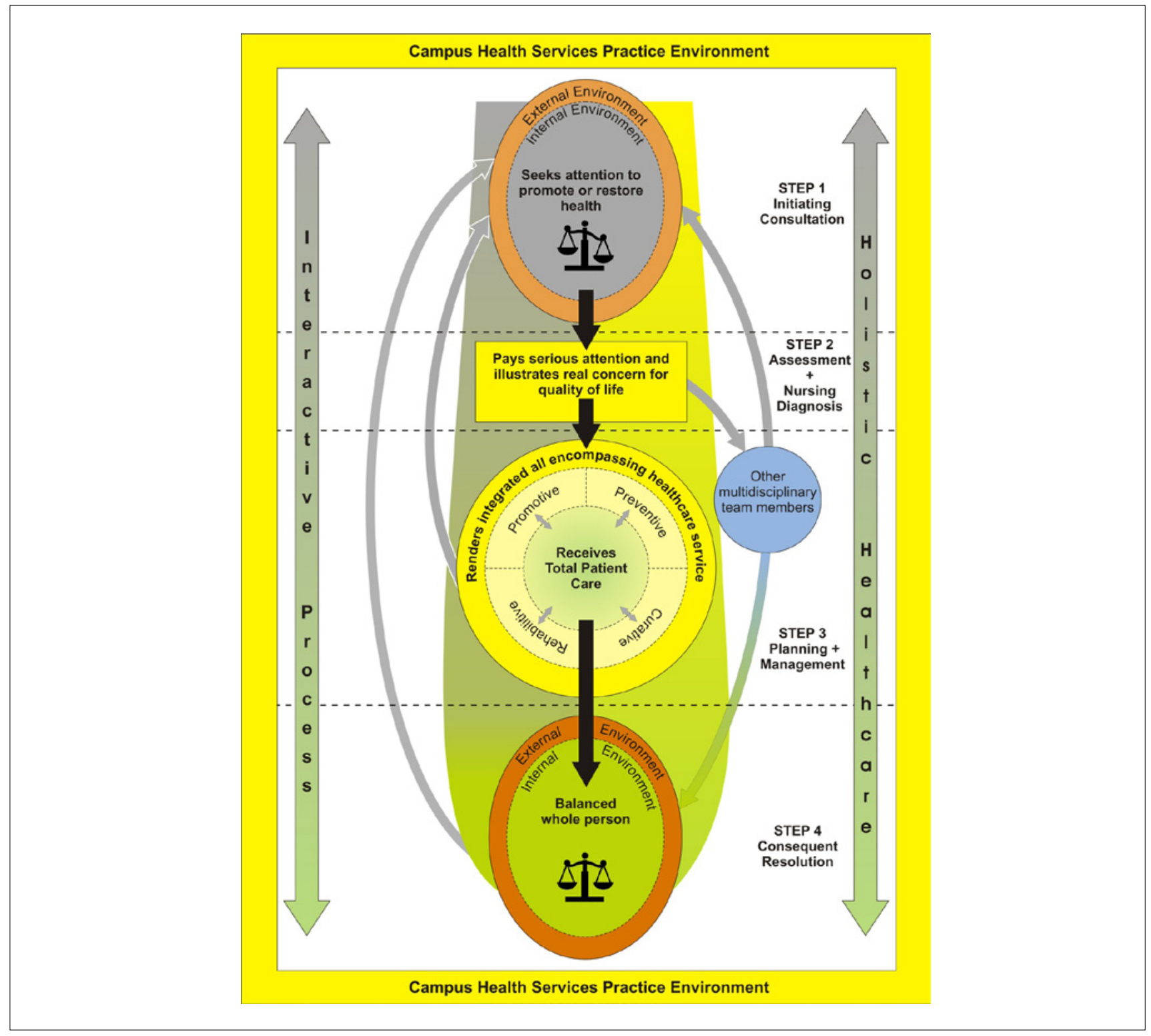




\section{An overview of the model}

Even though all the participants considered the current campus healthcare services rendered on campus to be of good quality, a need was expressed by all of them for a more holistic healthcare service to address a wider range of healthcare needs. This appeared to be an important aspect for most of the participants because good health was considered important for students and staff to become balanced whole persons so that they could realise their aspirations and maintain consistency with regard to optimum health and capacity. The latter could be due to the fact that HEIs place a lot of emphasis on achievement. In this model, health is therefore viewed as a process rather than an end product.

The registered nurse employed in a campus health service plays a pivotal role in assisting the students and staff on campus in achieving optimal health. She or he therefore has to pay serious attention to the healthcare needs of students and staff Concern for the quality of life is expressed when the registered nurse conducts a needs assessment and assesses individuals holistically in order to make a nursing diagnosis and to plan for treatment and further management. Thus an all-encompassing integrated healthcare service comprising promotive, preventive, curative and rehabilitative healthcare is necessary to ensure total patient care so that the campus healthcare consumers may become balanced, whole persons.

Figure 1 depicts a holistic healthcare model for a higher education institution's campus health service. As indicated in the model, the process of holistic healthcare in a higher education institution's campus health service progresses through four sequential steps consisting of initiating consultation, assessment and nursing diagnosis, planning and management and consequent resolution. Holistic healthcare is an interactive process taking place within a multidisciplinary team and could be repeated as the need arises. The campus healthcare providers render an integrated all-encompassing healthcare service comprising promotive, preventive, curative and rehabilitative services to ensure total patient care. This whole process contributes towards the gradual disappearance of the signs and symptoms or the empowerment of individuals with knowledge and skills for self-care resulting in the emergence of balanced, whole persons who are able to realise their aspirations and maintain consistency with regard to optimum health and capacity.

\section{The structure of the model}

The components of purpose, assumptions, context and theoretical definitions are addressed in describing the structure of the model.

\section{Purpose}

The purpose of this model is to provide a structured holistic healthcare frame of reference for registered nurses, employed in a campus health service at an HEI to assist all campus healthcare consumers to become balanced, whole persons who are able to realise their dreams and maintain consistency with regard to optimal health and capacity.

\section{Assumptions}

The model of 'Health care for all' propounded by the World Health Organization since 1978 (Van Rensburg 2004:32) serves as a point of departure for the assumptions of the holistic healthcare model as discussed below:

- The model is based on the assumption that holistic healthcare takes into account total patient care considering the physical, psychological, social, economic and spiritual needs of the campus healthcare consumers, their response to their illnesses and the effect of illness on their abilities to maintain consistency with regard to optimum health and capacity.

- The registered nurse will achieve holistic healthcare by focusing on primary health care as the means for achieving health for all on campus. Primary health care can thus be viewed as the vehicle for driving the process of holistic healthcare.

- Registered nurses must recognise that access to healthcare for all on campus is a basic human right which requires adequate human resources, infrastructure, essential drugs and commodities for the promotion of health and the management of disease(s).

- Registered nurses acknowledge and facilitate the need for multidisciplinary approaches to reduce the disease burden and promote health on campus.

- Registered nurses ensure that specific disease control programmes are strengthened and co-ordinated with other programmes and interventions; for example, the Department of Health and student counselling services.

- Registered nurses ensure that the campus healthcare system is responsive to the healthcare needs and expectations of the campus healthcare consumers and contribute to improving health outcomes and assist in the development of balanced whole persons.

- Registered nurses strengthen the partnerships with the financial, logistic, operational and scientific sections in order to improve their campus health service and disease control programmes and to orientate management and others to the healthcare needs of the campus healthcare consumers.

\section{Context}

The context of this model is that of the campus health service which is situated on the campus of an HEI in the western region of the Eastern Cape Province. It represents the work environment of the registered nurse who is confronted with a wide range of healthcare needs of a diverse campus healthcare consumer population. The campus healthcare population is extremely diverse in terms of gender, age, religion, culture, educational level and nationality. The registered nurse works independently and receives telephonic support from the doctor when needed or when she or he sees the patients who had been referred at the campus health service for one to two hours per week. The registered nurse is therefore responsible for ensuring that holistic healthcare is being made available to the campus healthcare consumers.

\section{The theoretical definitions of concepts}

The following definitions regarding the essential and related concepts have been developed by the researcher in order to provide conceptual clarity for the concepts applicable to the holistic healthcare model within the context of this study.

\section{Interactive process}

Holistic healthcare cannot solely be the responsibility of the registered nurse on campus because the healthcare needs of the campus healthcare consumers are diverse and they are active participants in the process of holistic healthcare. Thus the nurse has to exchange information with other members of the multidisciplinary healthcare team in order to obtain expert input which is extremely important in order to satisfy the diverse healthcare needs of an individual.

\section{Seeks assistance}

Individuals who experience a need to consult a healthcare professional for any health related need will go in search of a healthcare service where she or he can be attended to and/or receive advice.

\section{Promotes health}

Not all campus healthcare consumers who visit the campus health service are sick since they sometimes visit the clinic to obtain health related information, skills and preventive healthcare to maintain a healthy lifestyle. The registered nurse will contribute to the campus healthcare consumers' well-being on campus by providing services that will ensure the wellness of all students and staff. 


\section{Restores health}

Campus healthcare consumers who visit the campus health service because they are ill will be assisted with disease or symptom management by the registered nurse who renders a curative healthcare service on campus in order to correct the health imbalance. If the registered nurse is unable to treat and manage the campus healthcare consumer herself or himself, she or he will refer the person(s) to the next multidisciplinary team member who will assist with further management of the presenting health problem.

\section{Pays serious attention}

The registered nurse allows the campus healthcare consumer to verbalise his or her reasons for using the campus health service without interrupting her or him. She listens attentively to the spoken and unspoken word. Observations are made of the campus healthcare consumer's general appearance and the nurse probes her or him closely to obtain a comprehensive health history in order to make a nursing diagnosis. The registered nurse will also conduct a physical examination to obtain objective data to verify what the individual has reported.

\section{Giving of oneself}

Giving of oneself to another, is recognised as fundamental to caring. This involves physical, psychological and emotional giving, with voluntary sharing of oneself through the nurse's disclosing of personal information. Such a process develops a professional relationship with the individuals, while developing mutual trust. Such giving of oneself to the individual is experienced as communicating support to individuals with an understanding that the essential presence of a registered nurse can consequently reduce anxiety for the individual.

\section{Concern for quality of life}

The registered nurse on campus will take immediate action if she or he is worried about a situation that could be detrimental to all aspects of life, including health, recreation, culture, rights, values, beliefs, aspirations and the conditions that support a life containing these elements. Therefore the nursing care rendered on campus comprises conducting regular needs assessments and making a nursing diagnosis in order to empower, treat and provide personalised and culturally congruent healthcare to individuals exposed to suffering, or recovering from physical, psychological or spiritual ill health.

\section{Provision of an all-encompassing integrated health service}

Holistic healthcare is a comprehensive approach to healthcare that encompasses promotive, preventive, curative and rehabilitative health services. Therefore the latter approach to healthcare implies that body, mind and spirit consideration in all actions and interventions for the patient are implemented.

\section{Providing for needs}

Individuals are whole persons comprising body, mind and spirit, therefore the physical, psychological, spiritual and social healthcare needs of individuals must be provided for by the registered nurses within the individual's cultural context so that total patient care can be achieved.

\section{Balanced whole persons}

The perception of whole persons is dependent on the recognition that individuals comprise body, mind and spirit within the context of the environment and that this recognition is fundamental to holism. Thus healthcare delivery should meet the healthcare needs of the individual as a whole in order to achieve harmony amongst all dimensions of body, mind and spirit. The highest form of health and the goal of nursing care is related to the ability of individuals to maintain a balance with the environment, with relative freedom from pain, disability, or limitations, including social limitations. A balanced, whole person is one who is able to adapt to the environment successfully and who is able to grow, function and thrive in order to realise his or her aspirations and maintain consistency with regard to optimum health and capacity.

\section{Optimum capacity}

This term refers to a state where an individual is able to effectively perform roles and tasks expected of him or her in society. Individuals should therefore be able to continuously adjust to stressors in the internal and external environment through the most appropriate use of their resources in order to achieve maximum potential for daily living.

\section{A STRUCTURAL DESCRIPTION OF THE MODEL}

Figure 1 is a structural representation of a holistic healthcare model for a higher education institution's campus health services, which will serve as a basis for the discussion and explanation that follow.

The main feature of the model is the registered nurse who is the main role-player in expediting the holistic healthcare process so that the campus healthcare consumers can become balanced, whole persons who are able to realise their aspirations and maintain consistency with regard to optimal health and capacity. The structure of the model comprises four sequential steps and the black arrows running down the middle of the model indicate the direction the steps follow. The yellow and grey colours that run parallel in the background from Step 1 , which then gradually change into green, symbolises an increasing independence in the individual after Step 3 of the model signifying the changing relationship between the registered nurse and the campus healthcare consumer.

Initially, the campus healthcare consumer is dependent on the registered nurse for management and support, but gradually he or she will become empowered and well again and will therefore not need the support of the registered nurse. The relationship therefore gradually changes from one of dependence to independence. The two long dual-direction arrows on either side of the schematic centre structure of the model reflect that these four steps are interactive and that they comprise the holistic healthcare process. The yellow frame within which this structure exists represents the campus health services practice environment within which this whole process takes place.

Step 1 of the model indicates that the individual approaches the registered nurse because of a healthcare need that has arisen. The individual thus initiates consultation with the registered nurse either to promote or to restore health. This step is illustrated by a light orange outer circle illustrating the external environment and a grey inner circle illustrating an individual in need of healthcare. A broken line separates these two circles indicating that the individual exists within the external and internal environments and that both these environments could have an impact on the individual's well-being. The unbalanced scale in the internal environment signifies that the individual is experiencing an imbalance and therefore approaches the registered nurse to correct the imbalance.

The colour yellow is used to represent the registered nurse in Step 2 and Step 3. Step 2 forms the foundation for Step 3; therefore the registered nurse must pay serious attention to the healthcare needs of the campus healthcare consumers and illustrate real concern for their quality of life. The aforementioned will ensure that an adequate assessment is being made so that an accurate nursing diagnosis could be competently planned for and managed by the registered nurse. This step shows that 
the registered nurse could either immediately refer the campus healthcare consumer for further planning and management to the next multidisciplinary team member (depicted in the blue circle) without treating him or her if she feels that the current healthcare problem of the campus healthcare consumer is not within her scope of practice.

Step 3 shows that if the registered nurse plans and manages the healthcare consumer herself, she will address the physical, psychological and spiritual healthcare needs of the campus healthcare consumer to ensure that total patient care is being received. The aforementioned will be achieved by rendering an integrated all-encompassing healthcare service comprising promotive, preventive, curative and rehabilitative healthcare. The different shades of yellow with dotted lines are used to illustrate that the latter services are not separate but that they form an integrated service. The grey arrows that leave the yellow and blue circle and which are returning to Step 1 signify that the campus healthcare consumers did not respond to treatment and need to start the process again before becoming balanced, whole persons. Successful planning and management lead to Step 4.

Step 4 reflects that the consequent resolution of the whole process is a balanced, whole person who lives in harmony with the external and internal environments. The scale within the green circle symbolises the balanced state which may be permanent or transient. The grey arrow that returns from Step 4 to Step 1 indicates that the healthcare consumer could experience a need to return to the registered nurse for the same, or a new healthcare need.

\section{The process of the model}

The four sequential steps within which the process of holistic healthcare at an HEI's campus health service takes place are:

\section{Step 1: Initiating consultation}

The holistic healthcare process at HEIs commences when the campus healthcare consumer becomes aware of the healthcare services on campus and initiates consultation with the registered nurse at the campus health clinic to seek attention for either health promotion or restoration. Health is a private and sensitive matter and the nurse will acknowledge that the campus healthcare consumers are individuals who need personal privacy. Therefore the ethical principles of privacy, confidentiality, autonomy and beneficence will be adhered to at all times by those with whom the individual comes into contact at the campus health clinic.

The manner in which this initial step will be handled is extremely important because it could have an impact on the rapport and supportive relationship that will be established with the registered nurse and also the management of follow-up visits. The campus healthcare consumer is dependent on the registered nurse for support and management throughout Steps 1,2 and 3. Therefore the initial consultation will be conducted with the necessary privacy and sensitivity to ensure that a relationship of respect and trust develops between all those concerned.

\section{Step 2: Assessment and nursing diagnosis}

The registered nurse will pay serious attention to the healthcare needs of the healthcare consumers and give of herself. The nurse's giving of herself is recognised as fundamental to caring. This involves physical, psychological and emotional giving, with voluntary sharing by the nurse of herself through disclosing personal information. Such a process develops a professional relationship with individuals as people and the development of mutual trust. Such giving of oneself to the healthcare consumer is experienced as communicating support to healthcare consumers with an understanding that the essential presence of a nurse can consequently reduce anxiety for the healthcare consumer.

Real concern for the quality of life of the campus healthcare consumers will be demonstrated through warmth and kindness displayed by the registered nurse. The registered nurse will perform an assessment by taking an accurate health history and doing a physical examination in order to recognise abnormalities and to make a nursing diagnosis. She or he will screen patients and classify them according to those that she or he can help and those to be referred to other members of the multidisciplinary healthcare team. The registered nurse will not replace the doctor but will remain interdependent upon her or him for referral, for consultation and for the evaluation of her or his work.

\section{Step 3: Planning and management}

The third step of the holistic healthcare process involves active planning and management by the registered nurse for the healthcare needs of the campus healthcare consumer. She or he will assist with disease or symptom management or the maintenance of the campus healthcare consumers' health status by prescribing and dispensing medication, counselling them and teaching them health-promotive principles. The registered nurse will therefore render an integrated all-encompassing healthcare service on campus comprising promotive, preventive, curative and rehabilitative care.

By making all the above mentioned services available to the campus healthcare consumers, the registered nurses will ensure that all campus healthcare consumers receive total patient care which takes into account the physical, emotional, social, economic and spiritual needs of individuals, their response to their illnesses and the effect of illness on the individual's abilities to meet self-care needs and realise their aspirations and maintain consistency with regard to health and capacity.

There will be times though when the campus healthcare consumers will not respond to the treatment provided by the registered nurses or the other healthcare professionals; they will then return to Step 1 and the whole process will restart before the individual proceeds to Step 4 . If the planning and management are successful in Step 3 then the individual will proceed to Step 4.

\section{Step 4: Consequent resolution}

Stanhope and Lancaster (2002:136) indicate that the resolution of disease in the 'stage of disease process' is death, disability or recovery. The consequent resolution for this model will be the gradual disappearance of the signs and symptoms or the empowerment of an individual for self-care which will result in a balanced, whole person who is able to successfully adjust to the tensions in the external and internal environments resulting in harmonious integration of body, mind and spirit. Individuals will therefore be able to realise their aspirations and satisfy their needs by maintaining consistency with regard to optimum health and capacity. But this balanced state could be transient and the individual would then return to Step 1 of the holistic healthcare process to correct the imbalance again.

\section{A description of the guidelines for operationalising the model}

Broad guidelines for operationalising the holistic healthcare model for a higher education campus health service were described within the context of the campus health service using the research findings and literature as the basis for formulating the guidelines. Broad guidelines were developed for each step of the holistic healthcare process with each of the guidelines having its own operational implications.

\section{CONCLUSION}

The above discussion provides a description of the steps utilised in the development of a holistic healthcare model for a higher education campus health service. The aforementioned steps include concept analysis, placing of the concepts in relationships, a description of the model and guidelines to operationalise the model. 
The purpose for developing the holistic healthcare model was to provide a holistic healthcare frame of reference for registered nurses employed in a campus health service that could assist them in rendering an all-encompassing integrated healthcare service for all students and staff on campus. It is envisaged that the application of the holistic healthcare model could assist all campus healthcare consumers to become balanced whole persons who are able to realise their dreams and maintain consistency with regard to optimal health and capacity.

It is recommended that the model be used by registered nurses at HEIs in rendering a holistic healthcare service to students and staff on campus and that it also be used in any nursing practice or education situation to promote holistic healthcare. Further research could be conducted to evaluate the model's effectiveness and feasibility if applied in practice so that it could be refined.

It can therefore be concluded that the holistic healthcare model if implemented will contribute to ensuring healthy and well balanced whole persons on campus who are able to effectively perform roles and tasks expected of them in society. Nurturing and protecting the health of students and staff on campus are essential for them to remain productive and innovative and achieve their maximum potential because the SA economy depends largely on healthy graduates entering the professional world.

\section{REFERENCES}

Chinn, P.L. \& Kramer, M.K., 1995, Theory and nursing. A systematic approach, Mosby Inc., United States of America.

Creswell, J.W., 2004, Research design, qualitative, quantitative and mixed approaches, 2nd edn., Sage Publications, Inc., Thousand Oaks.

Dickoff, J., James, P. \& Wiedenbach, E., 1968, 'Theory in a practice discipline. Part 1. Practice oriented theory', Nursing Research 17(5).

Holtzhausen, L., 1996, 'Student health services at tertiary institutions in South Africa', report presented at the South African Campus Health Association Annual Conference, Blue Waters Hotel, Durban, pp. 1-100.

Patrick, K., Grace, T.W. \& Lovato, C.Y., 1992, 'Health issues for college students', Annual Review Public Health 13, 253-268.

Stanhope, M. \& Lancaster, J., 2002, Foundations of community health nursing. Community orientated Practice, Mosby Inc., United States of America.

Van Rensburg, H.C.J., 2004, Health and health care in South Africa, 4th edn., Van Schaik Publishers, Pretoria.

Walker, L.O. \& Avant, K.C., 1995, Strategies for theory construction in nursing, 3rd edn., Appleton and Lange, Norwalk.

Walker, L.O. \& Avant, K.C., 2005, Strategies for theory construction in nursing, 4th edn., Pearson Education Inc., New Jersey. 